\title{
Monitoring of organochlorine pesticides in the surface waters from Mid-Black Sea Region, Turkey
}

\author{
Feza Geyikçi • Hanife Büyükgüngör
}

Received: 26 August 2009 / Accepted: 11 February 2010 / Published online: 9 March 2010

(C) The Author(s) 2010. This article is published with open access at Springerlink.com

\begin{abstract}
The levels of 16 organochlorine pesticides (OCPs) in surface water in Mid-Black Sea Region in Turkey were investigated to evaluate their potential pollution and risks. The analysis of OCPs extracted by C-18 solid phase extract was performed using Fisions Mega II Series gas chromatograph coupled by electron capture detector. Surface water samples have been collected seasonally from ten rivers for a period of 1 year. The most commonly encountered OCPs in surface water were the isomers of hexachlorocyclohexane, dieldrin, p,p-DDD, and heptachlor epoxide. In some cases the concentrations detected were higher than the qualitative target levels set by the European Union, especially for $\delta$ hexachlorocyclohexane. The concentration levels found are lower than the EU maximum acceptable concentration of $0.10 \mu \mathrm{g} / \mathrm{l}$ for all compounds examined, except for $\delta-\mathrm{HCH}$ in two samples $\left(0.2505 \mu \mathrm{g} \mathrm{l}^{-1}\right.$ in the S-5 and $0.2046 \mu \mathrm{g} \mathrm{l^{-1 }}$ in the S-10). The occurrence of these compounds
\end{abstract}

F. Geyikçi $(\varangle)$

Department of Chemical Engineering,

Ondokuz Mayıs University,

55139 Kurupelit, Samsun, Turkey

e-mail: fezag@omu.edu.tr

H. Büyükgüngör

Department of Environmental Engineering,

Ondokuz Mayıs University,

55139 Kurupelit, Samsun, Turkey in Mid-Black Sea Region surface waters can be attributed to intense agricultural activity as well as to transboundary pollution.

Keywords Organochlorine pesticides •

Solid phase extract $\cdot$ Surface water .

Black Sea Region

\section{Introduction}

Pesticides, with their high degree of toxicity, constitute a very important group of target compounds in environmental samples. Because of their widespread use, they are detected by determination of their residues in various environmental matrices, such as soil, water, and air. Those present in waters may have an agricultural, domestic, or industrial origin, the most harmful effect being their inclusion in the so-called "nutrition chain". Environmental pollution by pesticides is a major environmental concern (López et al. 2001; Vinas et al. 2002). Organochlorine pesticides are known to resist biodegradation and therefore they can be concentrated through food chains and produce a significant magnification of the original concentration at the end of the chain (Sankararamakrishnan et al. 2005). Pesticides are one class of compounds that, despite their benefits, may produce a wide range of toxic side effect that pose a potential hazard to the envi- 
ronment (Golfinopoulos et al. 2003). While pesticides are indispensable in modern agriculture, their use or misuse may lead to serious water quality problems (Wauchope et al. 1994; El-Kabbany et al. 2000). Pesticide contamination surface and groundwaters from agricultural use has been well documented around the world (Wauchope et al. 1994; Hairston et al. 1995).

Many organochlorine pesticides (OCPs) were used on a global scale from the 1950s to the mid1980s, most of which are stable and persistent in the environment. Usage of OCPs has been prohibited in most countries including Turkey (Barra et al. 2001; Turgut 2003). Although drinking water contamination from pesticides is rare, it is possible under certain conditions. In 1995, pesticide usage in Turkey amounted to almost 37,000 tons (Besbelli 1998). An extremely toxic pesticide can cause the death of fish and other aquatic organisms even at low concentration. They have been reported to alter various reproduction functions in various animals including marine populations. Most surface waters (except deep lakes) have a rapid turnover rate, which means that freshwater dilutes the concentration of the contaminant quickly. In addition, most surface waters contain free oxygen, which enhances the rate at which pesticides are broken down by microorganisms. Pesticides applied immediately before a heavy rain may wash into streams or other surface waters and threaten fish and wildlife. For these reasons, usage of pesticides directly around a drinking water source would be forbidden (Bonner 1993; Pesando et al. 2004).

The success of raw water treatment should be examined by pesticide monitoring of the distributed potable water. Certain kinds of older pesticides, such as $\gamma-\mathrm{HCH}$ which may contain persistent $\alpha$ - and $\beta$-isomers are still present in the agricultural and could cause the residue problem. Pesticides sorbed to particulates are transported by streams and surface waters (Aydın and Yurdun 1999).

Monitoring studies in European countries have shown widespread detection of pesticides in ground and surface water. The levels of pesticides detected in water depend largely on the intensity of agricultural production in a given region. As the council directive 80/778 of the European
Union (EU) limits the concentration of individual pesticide and toxic transformation products in drinking water to $0.10 \mu \mathrm{g}^{-1}$ and the total concentration to $0.50 \mu \mathrm{g} \mathrm{l^{-1 }}$, many methods have been developed for both sample preparation and chromatographic separation and detection. The most common methods of preconcentration of various classes of pesticides from water samples are liquid-liquid extraction and solid-phase extraction (SPE; Quayle et al. 1997; Vassilakis et al. 1998). Solid-phase extraction is a rapidly growing sample preparation method, used most frequently for extracting trace organics in aqueous matrices, prior to injection into a gas chromatography. C-18 SPE has been used in studies of specific materials such as trace metals, individual organic compounds, and pesticides as well as investigations into natural organic matter. Analytical methods for pesticide residues have their main application in the control of food for human consumption, especially in the control of fruit or vegetables and drinking waters since they are generally produced using direct application of pesticides (Nerin et al. 1998; Simjouw et al. 2005).

Information OCPs in sources of drinking water from Middle Black Sea Region is limited. These studies describe the organochlorine pesticide result in surface waters in Middle Black Sea Region, which takes place in the north of Turkey. In Middle Black Sea Region, main sources of drinking water are the surface waters. Samsun, Sinop, Ordu, and Amasya cities take place in this region. Due to high annual rainfall in the region, floods result in transport of contaminants from agricultural areas to surface waters. The objective of the present study was to carry out the levels of various pesticide residues in surface waters.

\section{Materials and methods}

\section{Sampling}

Water samples were collected from ten surface waters from the streams in the Mid-Black Sea Region of Turkey in 1999. The study area is $27,228 \mathrm{~km}^{2}$. A total of ten sampling locations were identified by the water samples from agricultural area. Ten sampling sites were selected among the 


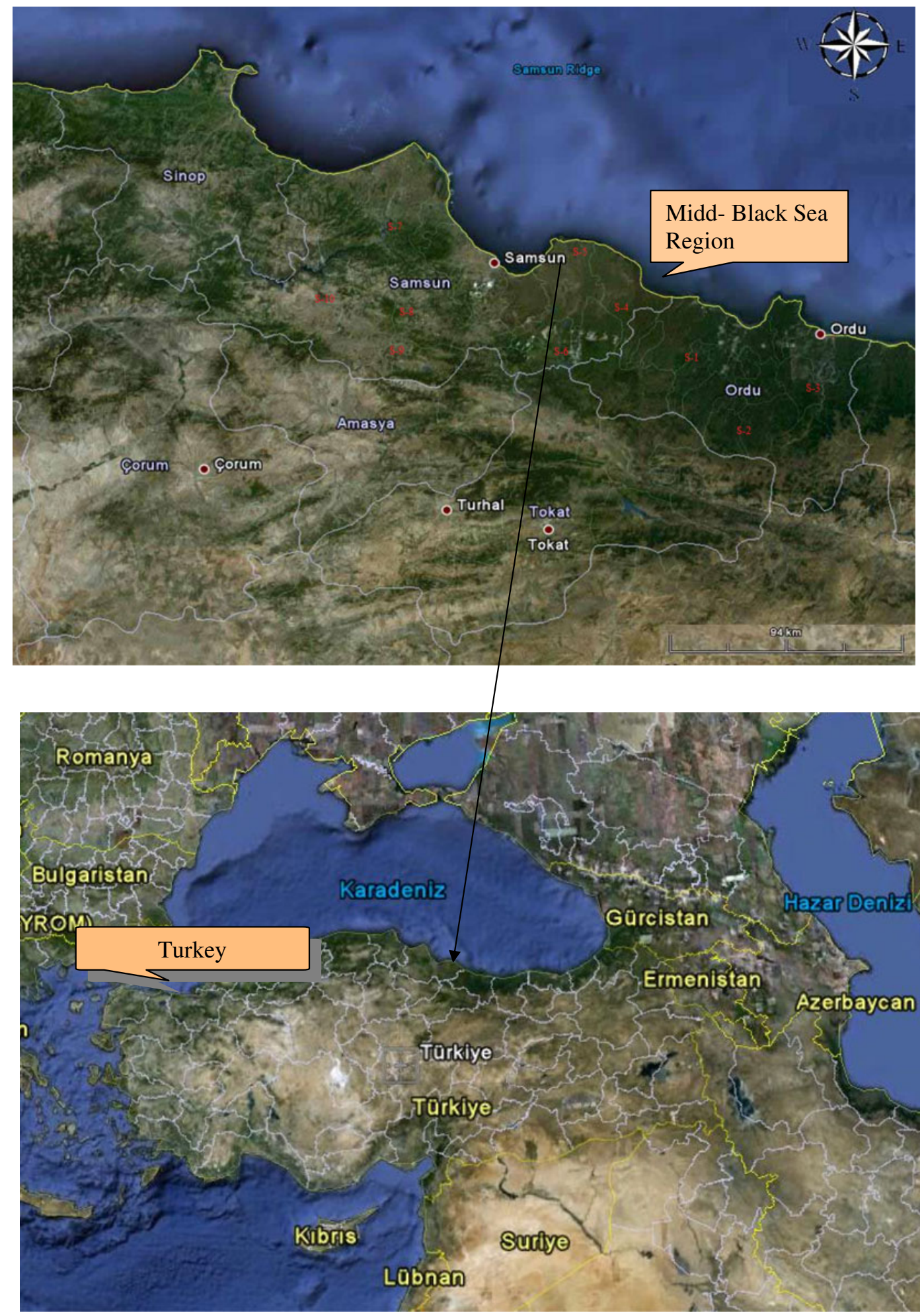

Fig. 1 Sampling locations in Mid-Black Sea Region. $S-1$ Devretci stream, $S$-2 Pencik stream, $S$-3 Karakaya stream, $S$-4 Corak stream, $S$-5 Camlica stream, $S$-6 Tamyeri stream,
S-7 Ortakoy stream, $S-8$ Sarialan stream, $S-9$ Uyuzsuyu stream, $S$-10 Bakircay stream 
locations determined source of drinking water by the Banks of Provinces and one water sample from each site was collected for survey. Water samples were collected three times per year. A total of 30 surface water samples at the water surface from Mid-Black Sea Region were collected during three axial surveys on November (winter), April (spring), and July (summer). Seasonal variations of pesticide detections in surface water according to the timing of pesticide applications related to sampling intervals have been noticed. Pesticide detections tended to be more frequent and more concentrated during the winter, spring, and summer months. Figure 1 shows the locations of sampling points. The surface waters are Devretci, Pencik, Karakaya, Tamyeri, Corak, Camlica, Ortakoy, Sarialan, Uyuzsuyu, and Bakircay.

At each location, samples were collected by strapping two 1-1 glass bottles. The vials were carefully filled just by overflowing, without passing air bubbles through samples or trapping air bubbles in sealed bottles. Preparation of vials included washing with detergent, rinsing with tap water then ultra-pure water, and air-dried. All samples were filtered through $0.45-\mu \mathrm{m}$ fiber glass filters to remove sand and debris after returning to the laboratory and extracted immediately.

\section{Analytical procedure}

Solid phase extraction disks followed by gas chromatographic techniques were used for the detection of organochlorine pesticides (APHA et al. 1992; Vidal et al. 1993; Shukla et al. 2006). The 11 samples were prefiltered by vacuum filtration through $0.45 \mu \mathrm{m}$ filter paper to remove particulates before pesticide extraction. All solvents used in pesticide extraction were high-pressure gas chromatography grade. All water samples were extracted using solid-phase extraction disks. The SPE disks used were 47-mm diameter Empore Disks for Environmental Analysis. Two milliliters of methanol was added to the water sample to keep the SPE disk conditioned during filtration. An extraction disk was placed on a sintered glass filter funnel apparatus attached to a vacuum source. A of total $10 \mathrm{ml}$ of a 1:1 methylene chloride/ethyl acetate solvent was added to the filter funnel as a cleaning solvent and was drawn through the disk at a rate of approximately $10 \mathrm{ml} \mathrm{s}^{-1}$. Air was then drawn through for $1 \mathrm{~min}$. Another $10 \mathrm{ml}$ of methanol was then added. As the solvent was drawn through, the vacuum was removed when a film of methanol covered the disk. This technique prevented drying and subsequent slow filtration through disk. The entire $250 \mathrm{ml}$ subsample was then added to the filter funnel and drawn through at approximately 25$30 \mathrm{ml} \mathrm{min}-1$, and the filtrate was discarded.

After the sample had been drawn through the disk, the vacuum was left on for 5 min to allow the disk to dry. The pesticides were eluted from the disk with two portions of $5 \mathrm{ml}$ of ethyl acetate and collected in glass vials (20-ml capacity) placed in the base of the vacuum manifold. During each addition of ethyl acetate, the vacuum was applied and removed quickly to allow some ethyl acetate to penetrate the entire disk thickness for $2 \mathrm{~min}$. Vacuum was then reapplied, and the remainder of the ethyl acetate was eluted into the glass vials. Anhydrous sodium sulphate $(4 \mathrm{ml})$ was added to the vial to remove any excess water. The final volume was brought to $5 \mathrm{ml}$ of ethyl acetate by a stream of dry nitrogen as the vials were immersed in a $30-35^{\circ} \mathrm{C}$ water bath. All extracts were further concentrated to about $1 \mathrm{ml}$. A volume of $0.3 \mu \mathrm{l}$ of dried solution was injected into the GC-ECD for analysis (Vidal et al. 1993; Senseman et al. 1997).

Experiments were carried out by using a Fisons HRGC Mega II Series gas chromatography (GC) equipped with a ${ }^{63} \mathrm{Ni}$ electron capture detector (ECD). The output of the ECD was connected to an integrator (Fisons, model DP 700). Chromatographic separation was achieved by using a fused silica capillary column $(30 \mathrm{~m} \times 0.25 \mathrm{~mm}$ i.d. $)$ coated with 5\% diphenyl-95\% dimethylsiloxane with film thickness of $0.25 \mu \mathrm{m}$ (Vidal et al. 1993; Columé et al. 2001; Golfinopoulos et al. 2003).

Nitrogen was used as the carrier gas and the injection technique was splitless. The gas chromatographic conditions used during analysis are shown in Table 1. The residues levels of OCPs were quantitatively determined by external standard method using peak area. The standard solution of composite OCPs including $\alpha-, \beta-$, $\gamma-$, and $\delta$-HCH; p,p'-DDE; p,p'-DDD; p,p'-DDT; heptachlor; heptachlor epoxide; aldrin; dieldrin; 
Table 1 Gas chromatographic conditions

\begin{tabular}{ll}
\hline Conditions & Values \\
\hline Carrier gas flow & $2 \mathrm{~mL} / \mathrm{min}$ \\
Makeup gas flow & $20 \mathrm{~mL} / \mathrm{min}$ \\
Oven temperature & $50^{\circ} \mathrm{C} / 1 \mathrm{~min}, 30^{\circ} \mathrm{C} / \mathrm{min}$ \\
& $180^{\circ} \mathrm{C} / 1 \mathrm{~min}, 6^{\circ} \mathrm{C} / \mathrm{min}$ to \\
& $220^{\circ} \mathrm{C} / 11 \mathrm{~min}, 5^{\circ} \mathrm{C} / \mathrm{min}$ \\
& to $250^{\circ} \mathrm{C} / 7 \mathrm{~min}$ \\
Injection port temperature & $250^{\circ} \mathrm{C}$ \\
Detector temperature & $280^{\circ} \mathrm{C}$ \\
\hline
\end{tabular}

endrin; endrin aldehyde; endosulfan I; endosulfan II; and endosulfan sulphate was purchased from Varian Associates, Inc.

Standard solutions were made up with ultrapure water, free from organochlorine pesticides by injecting known volumes of organochlorine pesticides solutions in methanol. The analytical quality-control scheme included periodic analy- ses of certified organochlorine pesticides standards and ultrapure water. The accuracy of determinations was routinely checked by using standard samples containing known amounts of organochlorine pesticides. Standard solution preparation was the following: a methanol stock solution of organochlorine pesticides standards was prepared in a $10 \mathrm{ml}$ volumetric flask filled with methanol. Known amounts of the stock solutions were added to $1,000 \mathrm{ml}$ of ultrapure in a volumetric flask to give standard water solutions. Mixing was accomplished by inverting the flask three or four times. Representative gas chromatogram of a standard solution is shown in Fig. 2.

\section{Results and discussion}

Results of sample analyses are summarized in Tables 2, 3, and 4. These analyses were carried out

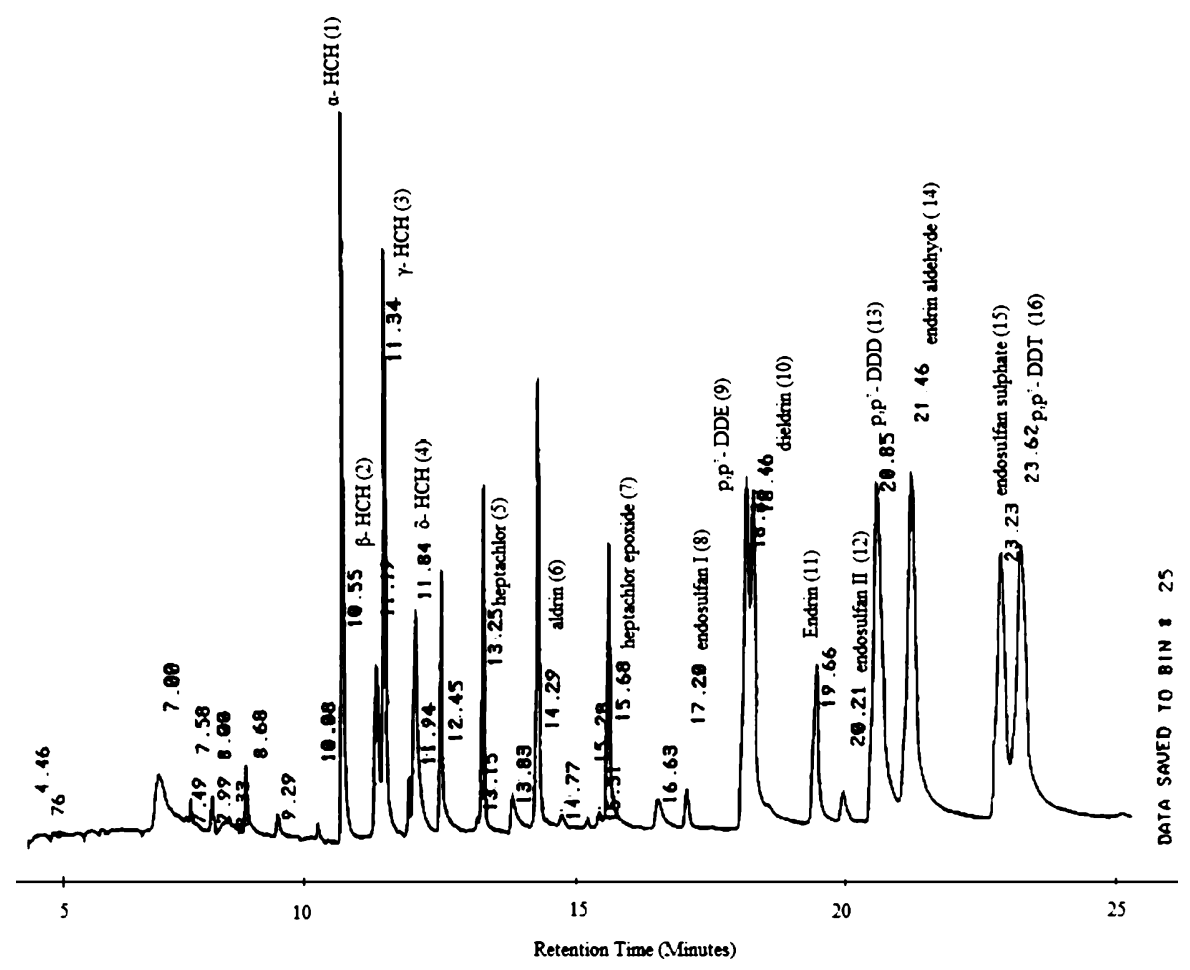

Fig. 2 GC-ECD chromatogram of a standard solution of $0.10 \mu \mathrm{l}$ organochlorine pesticides. Retention time and organochlorine pesticides: $\alpha-\mathrm{HCH}-10.55=(1)$, $\beta-\mathrm{HCH}-11.19=(2), \quad \gamma-\mathrm{HCH}-11.34-0=(3), \delta-$ $\mathrm{HCH}-11.84=(4)$, heptachlor-13.25 = (5), aldrin$14.29=(6)$, heptachlor epoxide-15.68=(7), endosulfan
$\mathrm{I}-17.20=(8)$, p,p'-DDE-18.33 $=(9)$, dieldrin$18.46=(10)$, endrin-19.66 $=(11)$, endosulfan II$20.21=(12)$, p,p'-DDD-20.85 $=(13)$, endrin aldehyde$21.46=(14)$, endosulfan sulphate-23.23 = (15), p, p'$\mathrm{DDT}-23.62=(16)$ 
Table 2 Concentrations of organochlorine pesticides detected in the surface water samples from the Mid-Black Sea Region in winter months

\begin{tabular}{|c|c|c|c|c|c|c|c|c|c|c|}
\hline \multirow{2}{*}{$\begin{array}{l}\text { Organochlorine } \\
\text { pesticide }\end{array}$} & \multicolumn{10}{|c|}{ Concentrations $(\mu \mathrm{g} / \mathrm{l})$} \\
\hline & S-1 & $\mathrm{S}-2$ & S-3 & S-4 & $S-5$ & S-6 & S-7 & S-8 & S-9 & S-10 \\
\hline$\overline{\alpha-\mathrm{HCH}}$ & nd & nd & nd & 0.0005 & 0.0037 & nd & $\overline{\mathrm{nd}}$ & $\mathrm{nd}$ & nd & $\overline{\text { nd }}$ \\
\hline$\beta-\mathrm{HCH}$ & nd & nd & 0.0038 & 0.0058 & 0.0174 & nd & nd & nd & nd & nd \\
\hline$\gamma-\mathrm{HCH}$ & nd & nd & nd & nd & nd & 0.0042 & nd & nd & nd & nd \\
\hline$\delta-\mathrm{HCH}$ & nd & nd & nd & nd & nd & nd & nd & nd & nd & nd \\
\hline Aldrin & nd & nd & nd & nd & nd & nd & nd & nd & nd & nd \\
\hline Dieldrin & nd & nd & nd & nd & nd & nd & nd & nd & nd & nd \\
\hline Endrin & nd & nd & nd & nd & nd & nd & nd & nd & nd & nd \\
\hline Endrin aldehyde & nd & nd & nd & nd & nd & nd & nd & nd & nd & nd \\
\hline $\mathrm{p}, \mathrm{p}-\mathrm{DDE}$ & nd & nd & nd & nd & nd & nd & nd & nd & nd & nd \\
\hline p,p-DDD & nd & nd & nd & nd & nd & nd & nd & nd & nd & nd \\
\hline p,p-DDT & nd & nd & nd & nd & nd & nd & nd & nd & nd & nd \\
\hline Endosulfan I & nd & nd & nd & nd & nd & nd & nd & nd & nd & nd \\
\hline Endosulfan II & nd & nd & nd & nd & nd & nd & nd & nd & nd & nd \\
\hline Endosulfan sulfate & nd & nd & nd & nd & nd & nd & nd & nd & nd & nd \\
\hline Heptachlor & nd & nd & nd & nd & nd & nd & nd & nd & nd & nd \\
\hline Heptachlor epoxide & nd & nd & nd & nd & nd & nd & nd & nd & nd & nd \\
\hline
\end{tabular}

Europen Economic Commission Standards (EEC Council Directive 1980/778/EEC) for drinking water: the total pesticide level should not exceed $0.50 \mathrm{\mu g}^{-1}$ and individual pesticide should not be greater than $0.10 \mu \mathrm{g} \mathrm{l^{-1 }}$

$n d$ not detected

on samples from different localities and various surface waters in Mid-Black Sea Region. It is well known that most of the applied pesticides are subject to many transport and conversion product. Thus, they do not remain at their target site but often enter aquatic environment via soil percolation,

Table 3 Concentrations of organochlorine pesticides detected in the surface water samples from the Mid-Black Sea Region in spring months

\begin{tabular}{|c|c|c|c|c|c|c|c|c|c|c|}
\hline \multirow{2}{*}{$\begin{array}{l}\text { Organochlorine } \\
\text { pesticide }\end{array}$} & \multicolumn{10}{|c|}{ Concentrations $(\mu \mathrm{g} / \mathrm{l})$} \\
\hline & S-1 & $\mathrm{S}-2$ & S-3 & $\mathrm{S}-4$ & S-5 & S-6 & $\mathrm{S}-7$ & $\mathrm{~S}-8$ & S-9 & $\mathrm{S}-10$ \\
\hline$\overline{\alpha-H C H n d}$ & nd & nd & nd & nd & 0.0030 & nd & nd & nd & 0.0070 & 0.0004 \\
\hline$\beta-\mathrm{HCHnd}$ & nd & 0.0049 & nd & nd & nd & nd & nd & 0.0521 & 0.0061 & 0.0013 \\
\hline$\gamma-\mathrm{HCHnd}$ & nd & nd & nd & nd & nd & nd & nd & nd & nd & nd \\
\hline$\delta-\mathrm{HCH}$ & nd & nd & nd & nd & 0.2505 & nd & nd & 0.0234 & nd & 0.2046 \\
\hline Aldrin & nd & nd & nd & nd & nd & nd & nd & nd & nd & nd \\
\hline Dieldrin & nd & nd & nd & nd & nd & nd & nd & 0.0018 & nd & nd \\
\hline Endrin & nd & nd & nd & nd & nd & nd & nd & nd & nd & nd \\
\hline Endrin aldehyde & nd & nd & nd & nd & nd & nd & nd & nd & nd & nd \\
\hline $\mathrm{p}, \mathrm{p}-\mathrm{DDE}$ & nd & nd & nd & nd & nd & nd & nd & nd & nd & nd \\
\hline p,p-DDD & nd & nd & nd & nd & nd & nd & nd & nd & 0.0089 & 0.0016 \\
\hline $\mathrm{p}, \mathrm{p}-\mathrm{DDT}$ & nd & nd & nd & nd & nd & nd & nd & nd & nd & nd \\
\hline Endosulfan I & nd & nd & nd & nd & nd & nd & nd & nd & nd & nd \\
\hline Endosulfan II & nd & nd & nd & nd & nd & nd & nd & nd & nd & nd \\
\hline Endosulfan sulfate & nd & nd & nd & nd & nd & nd & nd & nd & nd & nd \\
\hline Heptachlor & nd & nd & nd & nd & nd & nd & nd & nd & nd & nd \\
\hline Heptachlor epoxide & nd & nd & nd & nd & nd & nd & nd & 0.0214 & nd & nd \\
\hline
\end{tabular}

Europen Economic Commission Standards (EEC Council Directive 1980/778/EEC) for drinking water: the total pesticide level should not exceed $0.50 \mu \mathrm{g} \mathrm{l}^{-1}$ and individual pesticide should not be greater than $0.10 \mu \mathrm{g} \mathrm{l^{-1 }}$

nd not detected 
Table 4 Concentrations of organochlorine pesticides detected in the surface water samples from the Mid-Black Sea Region in summer months

\begin{tabular}{|c|c|c|c|c|c|c|c|c|c|c|}
\hline \multirow{2}{*}{$\begin{array}{l}\text { Organochlorine } \\
\text { pesticide }\end{array}$} & \multicolumn{10}{|c|}{ Concentrations $(\mu \mathrm{g} / \mathrm{l})$} \\
\hline & S-1 & $\mathrm{S}-2$ & S-3 & S-4 & $S-5$ & S-6 & $\mathrm{S}-7$ & S-8 & S-9 & S-10 \\
\hline$\overline{\alpha-H C H n d}$ & $\overline{\mathrm{nd}}$ & $\mathrm{nd}$ & 0.0003 & nd & $\overline{\mathrm{nd}}$ & nd & $\mathrm{nd}$ & nd & nd & $\overline{\mathrm{nd}}$ \\
\hline$\beta-\mathrm{HCHnd}$ & nd & nd & nd & 0.0023 & nd & nd & nd & nd & nd & nd \\
\hline$\gamma-\mathrm{HCHnd}$ & nd & nd & nd & nd & nd & nd & nd & nd & nd & nd \\
\hline$\delta-\mathrm{HCH}$ & nd & nd & nd & nd & nd & nd & nd & nd & nd & nd \\
\hline Aldrin & nd & nd & nd & nd & nd & nd & nd & nd & nd & nd \\
\hline Dieldrin & nd & nd & nd & nd & nd & nd & nd & nd & nd & nd \\
\hline Endrin & nd & nd & nd & nd & nd & nd & nd & nd & nd & nd \\
\hline Endrin aldehyde & nd & nd & nd & nd & nd & nd & nd & nd & nd & nd \\
\hline p,p-DDE & nd & nd & nd & nd & nd & nd & nd & nd & nd & nd \\
\hline p,p-DDD & nd & nd & nd & nd & nd & nd & nd & nd & nd & nd \\
\hline p,p-DDT & nd & nd & nd & nd & nd & nd & nd & nd & nd & nd \\
\hline Endosulfan I & nd & nd & nd & nd & nd & nd & nd & nd & nd & nd \\
\hline Endosulfan II & nd & nd & nd & nd & nd & nd & nd & nd & nd & nd \\
\hline Endosulfan sulfate & nd & nd & nd & nd & nd & nd & nd & nd & nd & nd \\
\hline Heptachlor & nd & nd & nd & nd & nd & nd & nd & nd & nd & nd \\
\hline Heptachlor epoxide & nd & nd & nd & nd & nd & nd & nd & nd & nd & nd \\
\hline
\end{tabular}

Europen Economic Commission Standards (EEC Council Directive 1980/778/EEC) for drinking water: the total pesticide level should not exceed $0.50 \mathrm{\mu g}^{-1}$ and individual pesticide should not be greater than $0.10 \mu \mathrm{g} \mathrm{l^{-1 }}$

$n d$ not detected

air drift, or surface runoff affecting abundance and diversity of non-target species producing complex effects on the ecosystems and altering tropic interactions (Sankararamakrishnan et al. 2005). Throughout the studied period, the isomers of $\mathrm{HCH}$ were found in S-2, S-3, S-4, S-5, S-6, S-8, S-9, and S-10. It is evident from Tables 2, 3, and 4 that out of the ten locations analyzed in agricultural area, samples contained $\mathrm{HCH}$ in the range of $0.0003-0.2505 \mu \mathrm{g}^{-1}$ predominant being $\beta-\mathrm{HCH}$.

Table 2 shows data on OCP residues in surface water samples collected from different parts of the region in winter months. In Table 2, the concentration range of pesticides was detected for $\alpha$-HCH $\left(0.0005-0.0037 \mu \mathrm{g} \mathrm{l}^{-1}\right), \beta-\mathrm{HCH}(0.0038-$ $0.0174 \mu \mathrm{g}^{-1}$ ), and $\gamma-\mathrm{HCH}$ (nd-0.0042 $\mu \mathrm{g} \mathrm{l}^{-1}$ ). $\alpha-\mathrm{HCH}$ was detected in both the Çorak and Çamlica Stream at the concentrations of 0.0005 and $0.0037 \mu \mathrm{g} \mathrm{l}^{-1}$, respectively. $\gamma-\mathrm{HCH}$ was only found in winter months in Tamyeri Stream. In the residue, levels were mostly found to be within WHO Guidline, Europen Economic Commission Standards (EEC Council Directive 1980/778/EEC) and Turkish Standard Values for drinking water quality (World Health Organization 1993; Turkish Standard 2005).

In Table 3, the concentration range of pesticides was for $\alpha$-HCH $(0.0004-0.0070 \mu \mathrm{g} / \mathrm{l}), \beta$ $\mathrm{HCH}\left(0.0013-0.0521 \mu \mathrm{g}^{-1}\right), \delta-\mathrm{HCH}$ (Table 3), $\delta-\mathrm{HCH} \quad\left(0.0234-0.2505 \mu \mathrm{g} \mathrm{1^{-1 }}\right.$ ), dieldrin (nd-

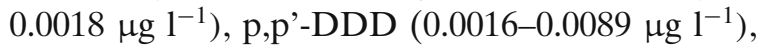
and for heptachlor epoxide (nd-0.0214 $\mu \mathrm{g} \mathrm{l}^{-1}$ ). Among the various pesticides analyzed only $\alpha$-, $\beta-$, and $\delta-\mathrm{HCH}$; dieldrin; p, p'-DDD; and heptachlor epoxide residues were found in the surface water samples in spring months. The highest concentration of $0.2505 \mu \mathrm{g} \mathrm{l}^{-1}$ was observed for $\delta-\mathrm{HCH}$. Heptachlor epoxide was present in the lowest concentration. Concentrations of dieldrin in this study were remarkably lower in comparison to other surface waters (Ayas et al. 1997; Turgut 2003; Golfinopoulos et al. 2003). Aldrin and dieldrin are closely related organochlorines. They were involved in numerous incidents of wildlife mortality. When aldrin is applied in the field, it is rapidly broken down to dieldrin (Turgut 2003). Figure 3 shows the chromatograms obtained with electron capture detection, for (S-8) Sarialan water samples. 
Fig. 3 GC-ECD

chromatogram of pesticides in a surface water sample (S-8)

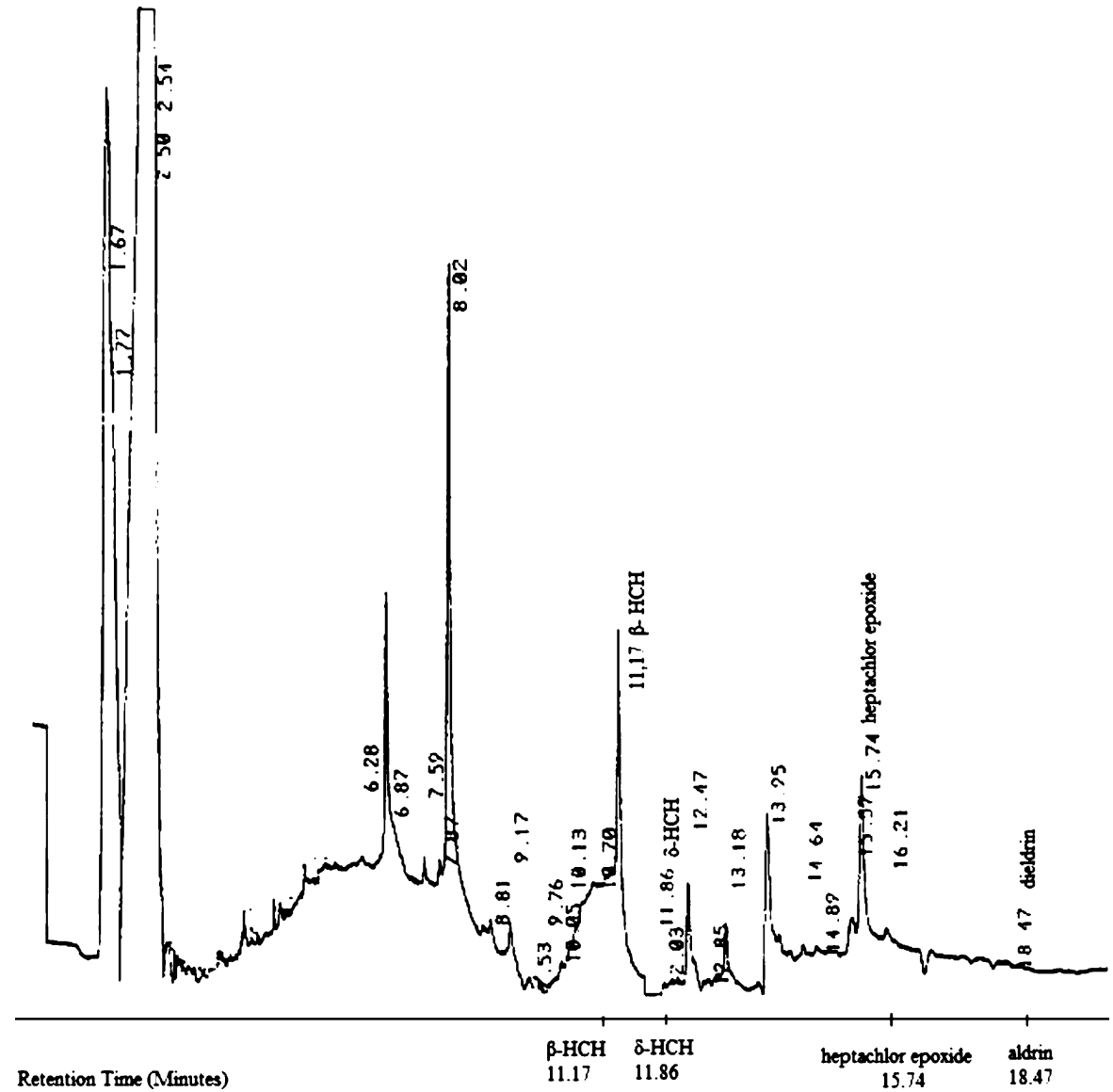

Table 4 illustrates results of water sample analyses in summer months. The highest values of the concentrations detected were $0.0003 \mu \mathrm{g} \mathrm{l^{-1 }}$ for $\alpha-\mathrm{HCH}$ and $0.0023 \mu \mathrm{g} \mathrm{l}^{-1}$ for $\beta-\mathrm{HCH}$ (Table 4). These values were much lower than those of winter and spring months.

In the surface waters, the highest concentrations of OCPs were $0.0070 \mu \mathrm{g} \mathrm{l^{-1 }}$ for $\alpha$ $\mathrm{HCH}$ (Table 3), $0.052 \mu \mathrm{g} \mathrm{l}^{-1}$ for $\beta-\mathrm{HCH}$ (Table 3), $0.0042 \mu \mathrm{g} \mathrm{l}^{-1}$ for $\gamma$-HCH (Table 2), $0.2505 \mu \mathrm{g} \mathrm{l} \mathrm{l}^{-1}$ for $\delta$-HCH (Table 3), $0.0018 \mu \mathrm{g}^{-1}$ for dieldrin (Table 3), $0.0089 \mu \mathrm{g} \mathrm{l}^{-1}$ for p,p'-DDD (Table 3), and $0.0214 \mu \mathrm{g} \mathrm{l}^{-1}$ for heptachlor epoxide (Table 3). The concentration of $\delta-\mathrm{HCH}$ was observed to be greater than other HCHs. In winter months, the concentration of $\delta-\mathrm{HCH}$ was lower than that in spring and summer months. It is obvious that water pollution due to OCPs was high. In accordance with Europen Economic
Commission Standards (EEC Council Directive 1980/778/EEC) for drinking water, the total pesticide level should not exceed $0.50 \mu \mathrm{g} 1^{-1}$ and individual pesticide should not be greater than $0.10 \mu \mathrm{g}^{-1}$. The concentration levels found are lower than the EU maximum acceptable concentration of $0.10 \mu \mathrm{g} 1^{-1}$ for all compounds examined, except for $\delta$-BHC in two samples $\left(0.2505 \mu \mathrm{g} \mathrm{l}^{-1}\right.$ in the S-5 and $0.2046 \mu \mathrm{g} \mathrm{l^{-1 }}$ in the S-10). These results demonstrate that there existed certain potential health risks to drinking water consumer in Mid-Black Sea Region.

The sources of OCP residues in the surface waters studied are agricultural practices within the region, in combination with rainfall. $\mathrm{HCH}$ isomers are the pesticides most frequently reported in recent studies of surface waters. The water level and the time of season's transformation also alter 


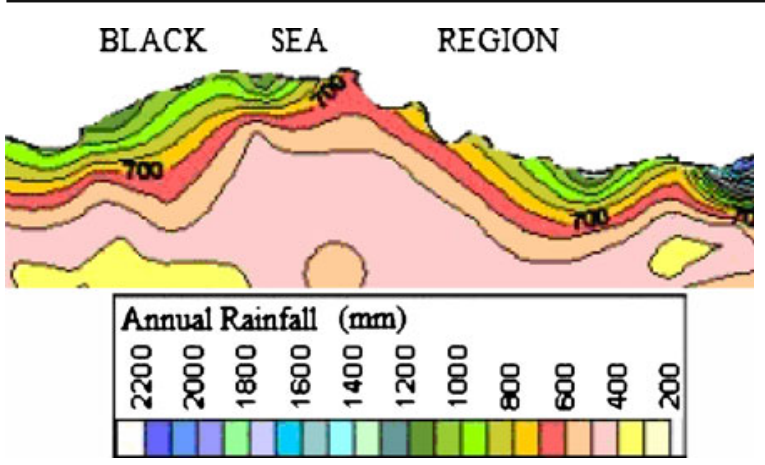

Fig. 4 Annual rainfall in the Black Sea Region

in each year due to the difference in the amount of rainfall and the climate around the surface waters (Geyikçi and Büyükgüngör 2002). The annual rainfall in the Black Sea Region was shown in Fig. 4.

The total concentration of OCPs also illustrates the lowest level in the dry season and highest in the rainy season. It is clearly revealed that the OCP residues in spring months were higher than the other sampling seasons. This meant that some OCPs could be released from wet deposition or soil eroding to waters with much rainfall during the winter and spring season in Mid-Black Sea Region. The high concentration of OCPs in the surface water could be attributed to the agricultural runoff resulting from the extensive agricultural activity in the banks of these locations. OCPs as a certain class of persistent organic pollutants have long biochemical half-lives in the environment. For instance, the biochemical half-life of DDT in the environment is at least 15 years. The persistent nature of OCPs and their translocation from agricultural land as runoff or as irrigation return flow can cause residues in water sources (Matin et al. 1998). In Turkey, groundwater levels are high and soils are usually coarse, which probably contribute to pesticide pollution of groundwater. It will take time for residues to decline in groundwater or to stop being leached into surface water (Geyikçi and Büyükgüngör 2002).

A monitoring in Black Sea Region showed that significant amounts of OCPs are detected in surface waters. DDT compounds had been banned in many countries (including Turkey; Turgut 2003).
The results found in this study were remarkably lower to those in other surface water in Turkey. The results of this survey show that the surface waters in the Mid-Black Sea Region have particular problems with respect to pesticide residues, so they cannot be used for the production of drinking water.

\section{Conclusion}

A number of surface water samples obtained from Mid-Black Sea Region were analyzed for presence of organochlorine pesticide residues in 1999. The compounds detected were $\mathrm{HCH}$ (the isomers $\alpha$-, $\beta-, \gamma-$, and $\delta-\mathrm{HCH}$ ), aldrin, dieldrin, endrin, endrin aldehyde, p, p'-DDD, p,p'-DDE, p,p'-DDT, endosulfan I, endosulfan II, endosulfan sulfate, heptachlor, and heptachlor epoxide.

Adopting pesticide use procedures that minimize or avoid the possibility of water contamination may mean a change in the usual practices of many pesticide users, but changes, when required, are essential. Levels of pesticides in water resources can be reduced by a regular process which would result with maximum protection of humans and the environment and minimum disruption of food and fiber production. Monitoring of the environment (including food, water, biota, soil, and air) for pesticide residues must continue.

This work provided the first systemic data on the contamination status of OCPs in surface water of Mid-Black Sea Region, Turkey. Due to previous excessive agriculture application, atmosphere transport, and difficulty of degradation, there still existed a variety of OCP residues in the surface waters in North Turkey. The occurrence of OCPs was studied in the surface waters of Northern Turkey for a period of three seasons in 1999. The levels of pesticide residues found ranged widely, from $0.0003 \mu \mathrm{g}^{-1}$ to $0.2505 \mu \mathrm{g}^{-1}$ for OCPs. The OCPs which have been detected are hexachlorocyclohexane (the isomers $\alpha-, \beta-$, $\gamma$-, and $\delta$-hexachlorocyclohexane), aldrin, dieldrin, endrin, endrin aldehyde, p, p'-DDD, p, p'DDE, p, p'-DDT, endosulfan I, endosulfan II, endosulfan sulfate, heptachlor, and heptachlor epoxide. In some cases the concentrations de- 
tected were higher than qualitative target levels set by the European Union, especially for $\delta$-hexachlorocyclohexane.

Moreover, the presence of OCPs in water is also attributed to intense agricultural activity in the area of Northern Turkey. Result confirms the presence of OCPs in the surface waters with low concentration.

Acknowledgements This work was supported by Global Environment Facility Project (GEF). The authors thank Bank of Provinces for their assistance in sample collection.

Open Access This article is distributed under the terms of the Creative Commons Attribution Noncommercial License which permits any noncommercial use, distribution, and reproduction in any medium, provided the original author(s) and source are credited.

\section{References}

APHA, AWWA, \& WPCF (1992). Standard methods for the examination of water and wastewater (18th ed.). Washington.

Ayas, Z., Barlas, N., \& Kolankaya, D. (1997). Determination of organochlorine pesticide residues in various environments and organisms in Göksu Delta, Turkey. Aquatic Toxicology, 39, 171-181.

Aydin, A., \& Yurdun, T. (1999). Residues of organochlorine pesticides in water sources of Istanbul. Water, Air, and Soil Pollution, 111, 385-398.

Barra, R., Cisternas, M., Urrutia, R., Pozo, K., Pacheco, P., Parra, O., et al. (2001). First report on chlorinated pesticide deposition in a sediment core from a small lake in central Chile. Chemosphere, 45, 749-757.

Besbelli, N. (1998). POPs related problems in Turkey. In Proceedings of the subregional meeting on national strategy and action plan for reducing/eliminating POPS releases, United Nations Environment Programme (UNEP). Moskow, Russian Federation 3-5.

Bonner, J. (1993). An environmental self-assessment handling and storing pesticides (pp. 1-13). Mississippi State University. Project Number, 1910.

Columé, A., Cardenas, S., Gallego, M., \& Vascarcel, M. (2001). Evaluation of an automated solid-phase extraction system fort he enrichment of organochlorine pesticides from waters. Talanta, 54, 943-951.

EEC Council Directive 80/778/EEC (1980). Official Journal of Europan Communities, 229, 11.

El-Kabbany, S., Rashed, M. M., \& Zayed, M. A. (2000). Monitoring of the pesticide levels in some water supplies and agricultural land, in El-Haram, Giza. Journal of Hazardous Materials, 72, 11-21.
Geyikçi, F., \& Büyükgüngör, H. (2002). Organik klorlu pestisitlerden benzen hegza klorür ve izomerlerinin yeraltı ve yüzey sularında oluşturduğu kirliliğin araştırılması. Çevre Bilimleri, 5, 39-46.

Golfinopoulos, K. S., Nikolaou, D. A., Kostopoulou, M. N., Xilourgidis, N. K., Vagi, M. C., \& Lekkas, D. T. (2003). Organochlorine pesticides in the surface waters of Northern Greece. Chemosphere, 50, 507-516.

Hairston, J. E., Balch, T., \& Laprade, J. C. (1995). Pesticide management to protect water quality understanding pesticides and how they affect water quality. Alabama Cooperative Extension Service. Auburn University Alabama wq-4-5.

López, F. J., Pitarch, E., Egea, S., Beltran, J., \& Hernández, F. (2001). Gas chromatographic determination of organochlorine and organophosphorus pesticides in humsan fluids using solid phase microextraction. Analytica Chimica Acta, 433, 217-226.

Matin, M. A., Malek, M. A., Amin, M. R., Rahman, S., Khatoon, J'., Rahman, M., et al. (1998). Organochlorine insecticide residues in surface and underground water from different regions of Bangladesh. Agriculture, Ecosystems and Environment, 69, 11-15.

Nerin, C., Batlle, R., \& Cacho, J. (1998). Determination of pesticides in high-water-content samples by off-line supercritical fluid extraction-gas chromatographyelectron-capture detection. Journal of Chromatography A, 795, 117-124.

Pesando, D., Robert, S., Huitorel, P., Gutknecht, E., Pereira, L., Girard, J. P., et al. (2004). Effects of metoxychlor, dieldrin and lindane on sea urchin fertilization and early development. Aquatic Toxicology, 66, 225-239.

Quayle, W. C., Jepson, I., \& Fowlis, I. A. (1997). Simultaneous quantitation of sixteen organochlorine pesticides in drinking waters using automed solid-phase extraction, high-volume injection, high-resolution gas chromatography. Journal of Chromatography A, 773, 271-276.

Sankararamakrishnan, N., Sharma, A. K., \& Sanghi, R. (2005). Organochlorine and organophosphorous pesticide residues in ground water and surface waters of Kanfur, Uttar Pradesh, India. Environment International, 31, 113-120.

Senseman, S. A., Lavy, T. L., Mattice, J. D., Gbur, E. E., \& Skulman, B. W. (1997). Trace level pesticide detections in Arkasas surface waters. Environmental Science \& Technology, 31, 395-401.

Shukla, G., Kumar, A., Bhanti, M., Joseph, P. E., \& Taneja, A. (2006). Organochlorine pesticide contamination of ground water in the city of Hyderabad. Environment International, 32, 244-247.

Simjouw, J., Minor, E., \& Mopper, K. (2005). Isolation and chracterization of estuarine dissolved organic matter: Comparison of ultrafiltration and C-18 solid phase extraction techniques. Marine Chemistry, 96, 219-235.

Turgut, C. (2003). The contamination with organochlorine pesticides and heavy metals in surface water in Küçük Menderes River in Turkey, 2002-2003. Environment International, 29, 29-32. 
Turkish Standard 266 (2005). Water intended for human consumption. Ankara.

Vassilakis, I., Tsipi, D., \& Scoullos, M. (1998). Determination of a variety of chemical classes of pesticides in surface and ground waters by off-line solid-phase extraction, gas chromatography with electron-capture and nitrogen-phosphorus detection, and high-performance liquid chromatography with post-column derivateization and fluorescence detection. Journal of Chromatography A, 823, 49-58.

Vidal, L. H., Trevelin, W. R., Landgraf, M. D., \& Rezende, M. O. O. (1993). Determination of organochlorine pesticides dissolved in water: A comparison between solid phase and solvent extraction. International Journal of Environmental Analytical Chemistry, 56, 23-31.

Vinas, P., Campillo, N., López-García, I., Aguinaga, N., \& Hernández-Córdoba, M. (2002). Determination of pesticides in waters by capillary gas chromatography with atomic emission detection. Journal of Chromatography A, 978, 249-256.

Wauchope, D. R., Baker, D. B., Balu, K., \& Nelson, H. (1994). Pesticides in surface and ground water. Agricultural Science and Technology, 2, 159-168.

World Health Organization (1993). Guidelines for drinking water quality (2nd ed., Vol. 1.). Recommendations, Geneva, Switzerland. 